Ano 5, Vol. 5 (2), n 2. 2020, agosto/dezembro de 2020

\title{
O movimento estudantil e a luta pela transformação da FUNESA em universidade de fato: uma análise sobre o período de 2005 a 2007
}

\author{
${ }^{1}$ Willames Nunes da Silva, ${ }^{2}$ Jemima Quézia Souza Silva, ${ }^{3}$ Luiz Gomes da Rocha \\ 1.Graduando de História da Uneal, E-mail: willamesn26@gmail.com, 2. Graduanda de História \\ da Uneal,E-mail: quezia.mima.jemima7@gmail.com, 3. Professor do Curso de História da Universidade \\ Estadual de Alagoas - Uneal, E-mail: luizotalagoas@yahoo.com.br
}

Resumo - A Universidade Estadual de Alagoas (UNEAL) tem na história de seus primórdios o marco indiscutível da participação singular do movimento estudantil atuante para a transformação da mesma em Universidade, dado que até então era apenas uma Fundação, a Fundação Universidade Estadual de Alagoas (FUNESA), título recebido após ser estadualizada. Visto isso, desde sua fundação foi necessária muita luta estudantil e docente para a sua manutenção e posterior transição dessa instituição de ensino superior privada para pública e gratuita; o processo de estatização foi fruto de muita luta. $\mathrm{O}$ mesmo ocorreu na transformação da FUNESA em UNEAL. Sendo assim, a partir de documentos conservados do movimento estudantil presentes no Grupo de Estudos de História e Movimentos Sociais (GEHMOV), num corte temporal de 2005 a 2007, de artigos e entrevistas com lideranças do movimento estudantil, além de questionários, seguindo o rigor metódico, o qual serviu de fonte oral para a construção do presente artigo, podemos reconstruir a conjuntura da época e a importante luta dos estudantes nesse processo.

Palavras-chave: movimento estudantil; universidade; Alagoas.

Abstract - The State University of Alagoas (UNEAL) has in the history of its beginnings the indisputable milestone of the singular participation of the student movement at work to transform it into a University, given that until then it was only a Foundation, the State University of Alagoas Foundation (FUNESA), title received after being nationalized. In view of this, since its foundation, it took a lot of student and teacher struggle for its maintenance and subsequent transition from this private to public and free higher education institution; the nationalization process was the result of much struggle. The same occurred in the transformation of FUNESA into UNEAL. Therefore, from documents preserved from the student movement present in the Study Group of History and Social Movements (GEHMOV), in a time cut from 2005 to 2007, from articles and interviews with leaders of the student movement, in addition to questionnaires, following the rigor methodical, which served as an oral source for the construction of this article, we can reconstruct the conjuncture of the time and the important struggle of students in this process.

Keywords: student movement; university; Alagoas. 
Ano 5, Vol. 5 (2), n $^{0} 2.2020$, agosto/dezembro de 2020

\section{Introdução}

A luta por direitos é uma constante e necessária prática social frente à opressão dos mais poderosos, que detêm os meios de produção e controlam a máquina do Estado. Apesar de todo esse poder, a luta de classes é o motor da história humana (MARX; ENGELS, 2018). Dessa maneira, a luta por conquistas de direitos se faz presente em todos os campos e estruturas sociais, principalmente no que se refere a educação e a disputa pela garantia de sua qualidade e gratuidade, como assegura e testifica a Constituição Federal do Brasil em seu artigo 205, ao afirmar que:

A educação, direito de todos e dever do Estado e da família, será promovida e incentivada com a colaboração da sociedade, visando ao pleno desenvolvimento da pessoa, seu preparo para o exercício da cidadania e sua qualificação para o trabalho. (2016, p. 123).

E se firmando como uma lei ainda mais incisiva, objetiva e democrática ao publicar as Emendas Constitucionais 2006, as quais garantem como sendo papel do Estado prover um ensino público gratuito e de qualidade, bem como assegura a autonomia didático-científica das universidades (BRASIL, 2016).

Desse modo, em associação a visão marxista das lutas sociais e em detrimento de se fazer valer a Constituição, o Movimento Estudantil se faz essencial em território nacional a fim de se colocar como o agente ativo que reivindica e assegura o cumprimento constitucional no que se refere as obrigações estatais para com as universidades. Ademais, a existência de um movimento estudantil participante e ativo só contribui para o crescimento acadêmico, pois "sua participação promove um amadurecimento político em seus estudantes que se reflete na construção de uma sociedade mais justa e igualitária" (MARTINS; CZERNISZ, 2017, p. 2), isto é, promove um envolvimento interno e externo ao meio universitário, incluindo toda a comunidade na luta por seus direitos.

É dessa forma que os movimentos estudantis no Brasil são tão essenciais quanto as próprias universidades, justamente pelo fato de que o histórico do sistema brasileiro em relação a educação ser precário, como descreve Darcy Ribeiro em sua obra intitulada Sobre o Óbvio (1986). Assim, Arthur Poerner, em seu livro O Poder Jovem (2004), sintetiza a necessidade, importância e motivação dos estudantes brasileiros:

Esse algo mais, que torna o estudante brasileiro muito mais maduro, politicamente, do que o seu colega europeu ou norte-americano, consta de uma profunda decepção quanto à maneira como o Brasil foi conduzido no passado, 
de uma violenta revolta contra o modo pelo qual ele é dirigido no presente e de uma entusiástica disposição de governá-lo de outra forma no futuro. (p.39).

Assim, constrói-se e desenvolve-se a luta estudantil em território nacional, com suas particularidades não vistas nos demais países. E, de maneira semelhante, essa luta por direitos acontece no estado de Alagoas, no nordeste do Brasil, de modo que, ocupada majoritariamente por faculdades e centros universitários privados, os quais serviam apenas as classes elitizadas do estado, os estudantes lutavam e lutam pela garantia constitucional do acesso às universidades públicas, as quais precisam revigorar qualidade e compromisso com as causas sociais.

Desse modo, considerando que, historicamente, as regiões interioranas, por serem locais mais afastados dos centros urbanos, tendem a necessitar de maior atenção quanto a investimentos na educação, faz-se necessária assim, a atuação ativa dos estudantes na manutenção da primeira, e durante muito tempo única, universidade pública do interior do estado, a Universidade Estadual de Alagoas (UNEAL), fundada na cidade de Arapiraca como uma instituição privada para formação de professores.

\section{Metodologia}

$\mathrm{O}$ artigo em questão, a respeito da metodologia de abordagem, trata-se de uma pesquisa qualitativa, fundamentada na teorização desenvolvida por Lüdke e André (1986) quanto a proximidade e abordagem do objeto de estudo e do que compõe a pesquisa no âmbito das ciências humanas voltadas à educação, visto que diz respeito a um tema teórico-subjetivo composto por uma análise da conjuntura estudantil alagoana, particularizando-se no caso da Universidade Estadual de Alagoas e sua luta por se constituir como universidade de fato.

Logo, não tem por objetivo ser consolidado como verdade absoluta (MARTINS, 2004), mas sim como uma interpretação cabível, como será visto, da realidade, dentro do recorte temporário selecionado, o qual consiste no intervalo de anos entre 2005 e 2007, período de intensas transformações no cenário acadêmico alagoano. Com a função de discursar sobre literatura, documentação e história oral, esta pesquisa pode se classificar como um trabalho bibliográfico-descritivo.

A dimensão histórica explorada por esta pesquisa concentra-se no campo da História Social, dialogando em alguns pontos com a História Política, de modo que diz respeito a um tema de interesse comum aos acadêmicos da História e de várias outras ciências sociais, bem 
Ano 5, Vol. 5 (2), $n^{0} 2.2020$, agosto/dezembro de 2020

como da população em geral, pois, engloba tanto análises do movimento estudantil, quanto dos movimentos sociais.

\section{Uma breve história da UNEAL}

A Universidade Estadual de Alagoas passou por alguns estágios antes de se tornar pública e gratuita. Foi criada como Fundação Educacional do Agreste Alagoano (FUNEC), sendo mantenedora da Faculdade de Formação dos Professores de Arapiraca (FFPA), na década de 1970. Tendo por mais de duas décadas funcionado como instituição privada é, finalmente, estadualizada por meio da Lei Estadual n. ${ }^{\circ}$ 5.762, de 29 de dezembro 1995, passando a ser intitulada como Fundação Universidade Estadual de Alagoas (FUNESA).

Determinada atitude consolida e amplia a FFPA, através do ensino gratuito expandindo até às cidades de Santana do Ipanema e Palmeiras dos Índios. Enquanto as licenciaturas em curta duração eram estabelecidas o Decreto Federal n. ${ }^{\circ}$ 79.866, de 27 de junho de 1977, abona os cursos existentes, mas é apenas em 1985 que a autorização para as licenciaturas plenas são liberadas através da Portaria Ministerial n. ${ }^{\circ}$ 145, de 26 de fevereiro, com os cursos de Letras (Português/Inglês e Português/Francês), Estudos Sociais e Ciências (Biologia, Física, Matemática e Química).

Evidente que a criação dessa instituição colabora para alçar a qualificação dos professores de toda região e municípios vizinhos, haja vista que as primeiras turmas foram formadas por professores da rede pública. E esse foi o primeiro passo dado em direção à qualificação de professores para o magistério em nível básico.

A FUNEC contribuiu durante duas décadas com a interiorização do ensino superior, mas, no final dos anos 1980 e início dos anos 1990, mergulhou numa grande crise financeira. Muitos alunos já não podiam pagar as anuidades e a política econômica do presidente Fernando Collor, com o confisco da poupança, agravava a situação.

O movimento estudantil propõe, então, a estadualização da FUNEC, bandeira ousada para a época, já que uma das principais pautas do governo federal era a privatização. No entanto, o movimento cresce e ganha o apoio dos professores e de setores da sociedade civil. As manifestações pela estadualização da FUNEC ganharam força e as mobilizações de quase dois anos foram dobrando a resistência do governo do Estado. Em vista disso, as manifestações estudantis foram contínuas, com noites de vigília no Palácio dos Martírios, onde a pressão era 
grande e o governador Moacir Lopes de Andrade (que assumiu o cargo depois do afastamento em 1989 de Fernando Collor de Mello para candidatar-se à Presidência da República) decidiu atender às reivindicações e aprovou a incorporação ao Executivo Estadual da FUNEC, por meio da Lei Estadual n. ${ }^{\circ}$ 5.119, de 12 de janeiro de 1990, tornando-a, assim, Pessoa Jurídica de Direito Público.

As despesas decorrentes de pagamento de professores e manutenção da própria instituição estariam garantidas com a execução desta Lei. Nos dias 11 e 14 de março de 1991, através dos Decretos Governamentais de números 34.830 e 34.877, são enquadrados no Estatuto dos Funcionários Públicos Civis do Estado (Lei Estadual n. ${ }^{\circ} 1.806$, de 18 de setembro de 1954), os Servidores do Quadro de Pessoal da Fundação do Agreste Alagoano - FUNEC, sendo publicado no Diário Oficial do Estado de Alagoas nas manhãs de terça e sexta-feira, respectivamente, 12 e 15 de março desse mesmo ano (1991). (ARAGÃO, 2010, p. 102-103).

A alteração do nome da Fundação Educacional do Agreste Alagoano (FUNEC) para Fundação Universidade Estadual de Alagoas (FUNESA) ocorreu através da Lei Estadual n. ${ }^{\circ}$ 5.762 de 29 de dezembro de 1995 . O ato teve diversas repercussões positivas. A crença coletiva era que a modificação do nome não se tratava apenas de uma mudança em sua nomenclatura, mas sim uma declaração subliminar de que o crescimento estava chegando para a Instituição. Porém, a situação da FUNESA não foi fácil nos anos seguintes, pois o Estado de Alagoas mergulhou na maior crise de História:

Escolas, maternidades e postos de saúde fechados, salários atrasados, sonegação fiscal atingindo um milhão de reais por dia e o crime organizado agindo impunemente. Mesmo diante da gravidade da crise, Suruagy seguia com zelo as recomendações de FHC. Transformava Alagoas num verdadeiro laboratório de sua política de destruição: fechamento de empresas, crescimento do desemprego, aumento da miséria, massacre do funcionalismo público, terceirizações, corrupção, falta de segurança pública, etc. (ROCHA, 2017, p. 29-30).

A política do governador Divaldo Suruagy desmantelou os serviços públicos, atrasou em mais de sete meses o pagamento dos salários dos servidores públicos estaduais e através do Programa de Demissão Voluntária, comandada por Luciano Barbosa, demitiu mais de vinte mil servidores. A FUNESA foi duramente atingida, houve diminuição de recursos e do quadro efetivo de professores.

Mas, a luta estudantil não parou, em 2003, no governo Ronaldo Lessa, o movimento conquista a realização de concurso público para professores. Novos docentes do Brasil inteiro chegam a Instituição, muitos com mestrados e doutorados. A nova realidade anima os 
estudantes, que junto com os docentes conquistam o direto de eleger por voto direto o presidente da FUNESA.

Com um quadro de professores efetivo significativo, o Sindicato dos Docentes da FUNESA, junto com o movimento estudantil e a Presidência da Instituição consegue formular e encaminhar aos órgãos superiores do Estado a solicitação para transformação da FUNESA em uma universidade. Após um período de avaliação, no ano de 2006, o Conselho Estadual de Educação, por meio do Parecer n. ${ }^{\circ}$ 100/2006, credencia a FUNESA como Universidade Estadual de Alagoas.

\section{O movimento estudantil nessa época}

Visto esse histórico de lutas e desafios enfrentado, no interior de Alagoas, a fim de que pudesse construir de fato uma universidade gratuita e de qualidade foi necessária a intensa movimentação dos estudantes da, até então, Fundação Universidade Estadual de Alagoas (FUNESA) para tentar derrubar o sistema interno presente que, por muitas vezes, contribuía para sua precarização. Assim, por meio de uma entrevista realizada com o candidato a presidência do Diretório Central dos Estudantes (DCE) do ano de 2005, Carlos Henrique Nunes ${ }^{1}$, foi possível traçar uma ideia de como funcionava o movimento estudantil dentro da futura UNEAL. Vejamos.

Segundo Carlos Henrique (2020), o que o movimento estudantil necessitava era da força de toda a comunidade acadêmica em prol de um objetivo comum para que, assim, sobre a bandeira de um bem maior, reunissem-se os estudantes a fim de conquistar os direitos violados pelo governo estadual no que diz respeito ao ensino superior gratuito e de qualidade local. Então, objetivando o apoio de todas as visões pró-UNEAL, a chapa candidata ao Diretório Central dos Estudantes deveria ser composta por estudantes dos mais variados cursos, para facilitar o diálogo com todos os Centros Acadêmicos e, semelhante a recriação da União Nacional dos Estudantes (UNE) no período pós-ditadura militar, para que todos pudessem, de forma organizada, reivindicar as melhorias desejadas e necessárias (FORTES et al., 2014).

Dessa forma, apesar do equívoco de alguns professores e alunos que apenas militam e buscam melhorias para seus respectivos cursos e áreas de pesquisa, a luta estudantil deve ser

\footnotetext{
${ }^{1}$ A íntegra das perguntas e respostas da entrevista estão disponíveis nas referências deste artigo.
} 
em conjunto, pois a pressão popular e das massas de forma organizada consiste na única maneira pela qual se alcançaram os direitos violados (GRABOIS, 1999). Em especial dentro do movimento estudantil, visto que no caso da FUNESA, foi através da mobilização feita por alunos de diversos cursos que o Sindicato dos Docentes da Fundação Universidade Estadual de Alagoas (SINDFUNESA) ganhou força, como relata o ex-presidente do DCE (2020), revigorou-se para lutar também pelos seus direitos em uma Instituição de ensino superior abandonada pelo governo.

Sendo assim, é destacado também pelo entrevistado, e evidenciado nos boletins divulgados na época e publicados no site do Grupo de Estudos História e Movimentos Sociais da UNEAL (GEHMOV), que a única maneira de se ter um movimento estudantil atuante e com voz ativa é rompendo laços com o corporativismo existente entre a hierarquia universitária, isto é, possuir autonomia dentro do meio acadêmico, pois só através da liberdade entre os poderes é que pode haver a discussão de ideias. Logo, segundo Carlos Henrique, dentro da FUNESA foi necessária a mobilização dos mais diversos setores acadêmicos, visto que, como o mesmo relata:

Muitos professores [eram] corporativistas de seus cursos, e naquela época na qual eu fui presidente do DCE, com a participação de estudantes de vários cursos [...] serviu para impulsionar os próprios professores, pois, eles percebendo a união da gente, exatamente por sermos alunos de cursos diferentes e de campus diferentes, a gente pode servir como exemplo para união e organização do próprio sindicato da FUNESA e eles puderam se organizar e lutar também por seus direitos. (NUNES, 2020).

Dessa maneira, a luta estudantil de 2005 na FUNESA englobou não somente os alunos, dado que as pautas levantadas pela Chapa 2 do DCE, composta por Carlos Henrique, abrangiam melhorias que beneficiariam a todos e, assim, pode estimular a organização dos docentes na universidade a fim de também reivindicar suas pautas. Então, conquistando a vitória sobre a Chapa 1, ligada a direção da Instituição, em 2005, os estudantes gozaram de um movimento estudantil livre, isto é, sem dependência frente a direção da instituição e do Estado, pois, como foi amplamente divulgado em campanha, constituíam-se num movimento autônomo na luta por melhorias coletivas para estudantes e professores.

Esse pensamento é a gênese do movimento estudantil, como bem destaca Arthur Poerner (2004, p. 324) ao afirmar que "os estudantes criaram as suas entidades livres (os Diretórios Centrais de Estudantes - DCEs). Livres, porque não nos submetemos às leis impostas pelas autoridades que não querem aceitar [a nossa opinião e reivindicações]" , ou seja, para se 
combater o sistema é necessário não compactuar com o mesmo. A autonomia se faz essencial frente às estruturas de poder seja na academia ou fora dela.

É dessa maneira que se tem a retomada do movimento estudantil na FUNESA no ano de 2005, quando a chapa "Por uma DCE Independente e uma Universidade de Fato" vence as eleições do DCE, pois significa a retomada do movimento estudantil independente e aliança com o movimento docente na luta pela transformação da FUNESA numa universidade de fato. Para isso, foi preciso um grande trabalho de mobilização para demonstrar os limites da Fundação, que, com recursos insuficientes, cobrava taxa para entrega de diploma, entre outras taxas que, segundo Carlos Henrique (2020), poderiam servir de pretexto para futuras cobranças mensais, acabando com o princípio da gratuidade da Fundação.

A visão política do movimento estudantil e do sindicato dos professores era em defesa da total gratuidade do ensino superior público, o que implica obrigatoriamente na isenção de quaisquer tipos de taxas que possam vir a serem cobradas aos alunos. Carlos Henrique resume essa posição contrária à cobrança de valores aos discentes, tomada pelo DCE, dizendo "a gente era a favor de uma universidade totalmente pública, gratuita, transparente e a gente tentou lutar por isso" (NUNES, 2020), ou seja, as entidades estudantis são acima de tudo entidades representativas dos interesses políticos estudantis, devendo se pautar por questões políticas de interesses coletivos.

\section{Embates políticos dos estudantes e administração}

A luta estudantil pela autonomia universitária é um capítulo importante da história do DCE, pois visava à conquista de autonomia de gestão e financeira frente ao Estado. E, nesse sentido, a aliança com os docentes era determinante. Quando a FUNESA elegeu seu primeiro diretor presidente, o governo do Estado negou-se a dar posse. Então, o movimento ganhou às ruas exigindo respeito a vontade soberana da comunidade acadêmica, expressando uma forte resistência contra o abuso de poder por parte do governo estadual.

O movimento foi vitorioso e o professor Dácio Brito foi empossado presidente da FUNESA, no ano de 2006. A respeito disso, relata Carlos Henrique (2020), que os estudantes e professores uniram-se para fazer cumprir a vontade da comunidade acadêmica quanto a quem seria seu presidente, visto que o professor Dácio Brito havia sido eleito democraticamente. 
Segundo o presidente do DCE da época "foi uma luta muito grande contra o governo de Ronaldo Lessa, pois eles queriam fazer outro tipo de manobra, como, por exemplo, uma lista tríplice para que o estado pudesse decidir quem seria reitor" (NUNES, 2020). Isso evidencia a questão política presente no sistema educacional, explicitando a compreensão erronia a respeito da FUNESA como sendo feudo do grupo governante e não como uma gestão democrática e coletiva. De igual modo, a disputa ideológica presente no sistema de educação consiste, como dissera Darcy Ribeiro, em um projeto de governo objetivando manipular o sistema a seu favor (RIBEIRO, 1986).

A luta construiu a necessária união acadêmica pela autonomia da FUNESA, exigindo respeito ao resultado das urnas e levando os estudantes a ocuparem o prédio principal da Instituição. Em 2006, ano em que é reconhecida como Universidade de fato, os estudantes, com apoio dos professores, resistiram contra a ameaça do uso da força policial. O movimento queria que fosse garantida e respeitada a vontade dos eleitores e não aceitava intervenção externa. A ocupação do prédio principal da reitoria, as manifestações em Arapiraca e as caravanas para Maceió terminaram por garantir a posse do professor Dacio Brito.

Assim, nós forçamos uma situação e o governo do estado foi obrigado a aceitar o que os estudantes e a comunidade acadêmica queriam, aceitar a democracia. Foi um movimento e um momento muito importante e uma das vitórias que movimento estudantil e o DCE, hoje, podem comemorar como atuantes no processo de transformação e autonomia da FUNESA. (NUNES, 2020).

Dessa maneira se fez valer a Constituição Brasileira dentro do movimento estudantil e sindical na antiga FUNESA, atual UNEAL, a qual diz que "as universidades gozam de autonomia didático-científica, administrativa e de gestão financeira e patrimonial, e obedecerão ao princípio da indissociabilidade entre ensino, pesquisa e extensão" (BRASIL, 2016, p. 123), ou seja, através da força da mobilização dos movimentos sociais que buscavam, dentro da FUNESA, qualidade, gratuidade e autonomia é há, hoje, no interior de Alagoas uma universidade que, mesmo com diversas dificuldades orçamentárias, oferece aos alagoanos um ensino superior de qualidade e gratuito, garantindo a oportunidade de acesso para todos.

Sendo assim, compreende-se o quão fundamental é o papel das entidades estudantis dentro da luta universitária pela garantia de seus direitos. São elas representantes oficiais da comunidade discente acadêmica, "as entidades estudantis são entidades dos estudantes, de todos os estudantes. O CA é o representante de todos os estudantes do curso [...] não importa se tem estudante católico, protestante ou ateu" (ROCHA, 2020), ou seja, independentemente da individualidade de cada estudante, o movimento estudantil é coletivo e, desse modo, deve travar 
suas pautas políticas em benefício de toda a universidade. A respeito disso, disserta o professor Luiz Gomes da Rocha:

Cuidar só da própria vida não é suficiente, além de cuidar da própria vida, tem que cuidar dos interesses enquanto estudante para ter um curso de qualidade, para ter seminários, eventos, para ter uma universidade viva. Então, os desafios são muitos nesse momento, desde as reivindicações imediatas até a luta por um país com direitos, soberano, justo, que é o que a gente almeja enquanto cidadão consciente. (ROCHA, 2020)

Assim, o movimento estudantil foi ativo e ocupou um espaço importante na FUNESA/UNEAL durante os anos de 2005 a 2007, visando defender as necessidades reais enfrentadas pelos estudantes no interior de Alagoas, as quais iam além de pautas internas de determinados cursos. Consistia numa luta maior pela defesa de uma Instituição de ensino superior pública, gratuita e de qualidade, e voltada aos filhos da classe trabalhadora do estado.

Portanto, através de diversas conquistas no processo de autonomia, o fim da cobrança de taxas, entre outras pautas, mostrou toda força e vitalidade do movimento estudantil, cuja liderança foi importante nesse capítulo da história da Universidade Estadual de Alagoas.

\section{Considerações finais}

O movimento estudantil que atuou na passagem de FUNESA para UNEAL, no período de 2005 a 2007, foi marcada pela participação política, objetivando mudanças reais dentro do âmbito acadêmico, fazendo assim com que divergisse de diversas vertentes da militância da época. Isso pode ser comprovado através dos panfletos publicados no site do GEHMOV, os quais explanam as propostas feitas pela chapa que disputou e venceu as eleições para o DCE da FUNESA, permitindo a luta que conquistou uma série de transformações no cenário universitário e do estado de Alagoas.

A posição política adotada pela nova direção do DCE demonstra a importância da participação dos estudantes para a manutenção e garantia das reformas democráticas dentro e fora da universidade. A respeito disso, a UNE se expressa a favor da atuação política e consciente do movimento estudantil, visto que o mesmo está a serviço de uma sociedade mais democrática. Portanto, a luta em defesa da autonomia universitária, pelo desenvolvimento do ensino, da pesquisa e da extensão, só é possível por meio de mais investimentos e do atendimento das necessidades enfrentadas nas universidades. 
Ano 5, Vol. 5 (2), $n^{0} 2.2020$, agosto/dezembro de 2020

Assim, através da história é possível perceber o papel fundamental do movimento estudantil nas pautas políticas do país, foi assim durante o combate à opressão da ditadura militar, é assim dentro das universidades de todos os estados (SANTANA, 2007), e foi assim no estado de Alagoas, na luta para a constituição de uma Universidade Estadual de Alagoas gratuita e de qualidade. De igual modo, é necessária a formação política de base por parte de tais entidades acadêmicas e partidárias, a fim de que o movimento estudantil atual, tal como o de 2005 a 2007 na UNEAL, seja combativo e priorize as demandas político-sociais da universidade.

\section{Conflite de interesse}

Os autores não declararam conflito de interesse no momento da submissão desse artigo.

\section{Referências}

ALAGOAS. Lei no 5.762, de 29 de dezembro de 1995. Altera o nome da FUNEC para FUNESA. Maceió: Palácio Marechal Floriano, 1995. Disponível em:

<https://gehmovuneal.blogspot.com/2020/07/lei-57621995-cria-funesa.html>. Acesso em: 02 jul. 2020.

ARAGÃO, Maria Helena de Melo. Ensino Superior na FUNESA: contextos e trajetória (1990-2006). 2010. Dissertação - Programa de Pós-Graduação em Educação, UFAL, Maceió, 2010.

BRASIL. Constituição (2016). Constituição da República Federativa do Brasil. Brasília, DF: Senado Federal, Coordenação de Edições Técnicas, 2016.

NUNES, Carlos Henrique. Entrevistadores: Willames Nunes; Jemima Quezia. Arapiraca-AL: WhatsApp, 2019. Entrevista ao Grupo de Estudos de História e Movimentos Sociais. Disponível em: https://gehmovuneal.blogspot.com/2020/06/gehmov-entrevista-presidentedo.html. Acesso em 22 jun. 2020.

FORTES, Alexandre; Corrêa, Larissa Rosa; FONTES, Paulo (org.). Dicionário Histórico dos Movimentos Sociais Brasileiros (1964-2014). Rio de Janeiro: UFRJ, 2015.

GEHMOV. Boletins e panfletos das eleições para o DCE de 2005. Disponível em: https://gehmovuneal.blogspot.com/2020/10/boletins-e-panfletos-das-eleicoes-para.html. Acesso em 05 out. 2020. 
Ano 5, Vol. 5 (2), $n^{0} 2.2020$, agosto/dezembro de 2020

GRABOIS, Maurício. Mobilizar Grandes Massas Para Defender a Paz e Derrotar o Imperialismo e a Ditadura. Disponível em:

https://www.marxists.org/portugues/grabois/1949/05/mobilizar.htm. Acesso em: 20 mar. 2020.

LÜDKE, Menga; ANDRÉ, Marli E. D. A. Pesquisa em educação: abordagens qualitativas. São Paulo: EPU, 1986.

MARTINS, Fernanda de Souza.; CZERNISZ, Eliane. C. da Silva. Movimento Estudantil: aspectos históricos e a atuação política na Universidade Estadual de Londrina. In: IV Jornada de Didática, 2017, Londrina. Anais da IV Jornada de Didática: Docência na Contemporaneidade. UEL: 2017.

MARTINS, Heloísa. H. T. de Souza. Metodologia qualitativa de pesquisa. Educação e pesquisa, São Paulo - SP, v. 30, n. 2, p. 289-300, maio/ago. 2004.

MARX, Karl; ENGELS, Friedrich. Manifesto do Partido Comunista. $1^{\text {a }}$ ed. São Paulo: Lafonte, 2018.

POENER, Arthur. O Poder Jovem: história da participação política dos estudantes desde o Brasil-Colônia até o governo Lula. $5^{\text {a }}$ ed. Rio de Janeiro: Booklink, 2004. RIBEIRO, Darcy. Sobre o óbvio. Rio de Janeiro: Guanabara, 1986.

ROCHA, Luiz Gomes da. O Levante de 1997: Policiais civis e militares na derrubada do governador Suruagy. Maceió: Edições Nosso Mundo, 2017.

Contribuições sobre a História, concepções e desafios do movimento estudantil na UNEAL. Disponível em: <https://gehmovuneal.blogspot.com/2020/06/contribuicoessobre-historia-concepcoes.html>. Acesso em: 02 jul. 2020.

SANTANA, Flávia de Angelis. Atuação Política do Movimento Estudantil no Brasil: 1964 a 1984. São Paulo: USP, 2007. 